\title{
Oxygen-Ozone Therapy is an Effective Therapy in Chronic Fatigue Syndrome: Results in 100 Patients
}

\author{
Umberto Tirelli*, Cinzia Cirrito and Martina Pavanello \\ Tumour Centre, CFS, Fibromyalgia and Oxygen Ozone Therapy Unit, Tirelli Medical Clinic, Italy \\ *Corresponding author: Umberto Tirelli, Tumour Centre, CFS, Fibromyalgia and Oxygen Ozone Therapy Unit, Tirelli \\ Medical Clinic, Pordenone, Italy
}

\section{ARTICLE INFO}

Received: September 11, 2019

Published: 慧 September 19, 2019

Citation: Umberto Tirelli, Cinzia Cirrito, Martina Pavanello. Oxygen-Ozone Therapy is an Effective Therapy in Chronic Fatigue Syndrome: Results in 100 Patients. Biomed J Sci \& Tech Res 21(3)-2019. BJSTR. MS.ID.003602.

Keywords: Ozone therapy; Chronic Fatigue Syndrome; Fatigue

\section{ABSTRACT}

Objective: The Centres of Disease Control first described the Chronic Fatigue Syndrome (CFS) at the end of 1980s. Since the last few decades, the therapeutic potential of ozone has gained much attention: in fact, when administered in precise therapeutic doses, oxygen-ozone therapy is active in many diseases.

Patients and Methods: At the Tirelli Medical Clinic in Pordenone, Italy, from February 2016 to December 2018, we have treated 100 patients, with auto hemo-transfusion, according to the SIOOT (Scientific Society of Oxygen Ozone Therapy) protocols, twice a week for one month and twice a month as maintenance therapy.

Results: Females were 80, males were 20; age ranged from 13 to 60 years and the time from CFS diagnosis ranged from 1 to 15 years. To assess the extent of fatigue we employed the Fatigue Severity Scale which is used to estimate the severity of the symptom with a score ranging from 1 to 7 . Of the 100 patients with CFS we have treated, 70 patients $(70 \%)$ showed a significant improvement in symptomatology $(>50 \%$ improvement in symptoms). There have been no side effects to oxygen-ozone therapy.

Conclusion: In conclusion, at our knowledge this is the largest study of patients with CFS treated with ozone therapy. Oxygen ozone therapy is an effective therapy in the treatment of CFS.

\section{Introduction}

The myalgic encephalomyelitis and the chronicfatigue syndrome (ME/CFS), are described as a multifaceted physical complaint. ME/ CFS patients often suffer for incapacitating fatigue, massive energy crashes after minor exertion (post-exertional malaise - PEM), tenderness, cognitive problems, sleeping disorders and many other neurological, immunological and autonomic symptoms. PEM is the main symptom of CFS, it causes the aggravation of its symptoms after minimal physical or even mental activity. Exhaustion may last for long, sometimes days or even weeks. Rest and sleep have only little relief of fatigue and the other symptoms. Another characteristic of CFS is the considerably reduced physical and/ or cognitive functioning [1]. Even if ME/CFS is a physical illness, many patients also suffer from secondary psychological symptoms. This is however common in many chronic conditions [2-5]. The term myalgic encephalomyelitis (ME) was first used in 1956 in
London, England describing a well-documented cluster outbreak of a fatiguing illness.

The name Chronic Fatigue Syndrome (CFS) replaced the previous name, Chronic Epstein-Barr virus syndrome, in 1984 in Nevada (USA), following the study of a cluster outbreak of a alike fatiguing illness, because clinical studies did not confirm Epstein-Barr virus as the presumed cause. The name chronic fatigue syndrome CFS - was criticized because considered vague and trivializing of the illness; it can also be confused with the common non-specific complaint of chronic fatigue. The disease is also identified with myalgic encephalopathy or with CFIDS (chronic fatigue immune dysfunction syndrome). The World Health Organization classifies $\mathrm{ME}$ as a central nervous system illness (G93.3.). Post-viral fatigue syndrome (PVFS), a similar disease, describes the persistent fatigue due to a viral infection [6-11]. The name CFS is used in the USA 
and Australia while ME is more common in Europe and Canada. The name "CFS" is the most use in studies following the specific case definition written for this purpose by Fukuda et al. in 199412, worldwide ME/CFS or CFS/ME are being used more often.

The majority of CFS patients are isolated cases, even though cluster outbreaks of CFS have been described all over the world; Iceland (1948), London, Great Britain (1955), New Zealand (1984), and the USA (Nevada, 1984; New York State and North Carolina, 1985). CFS patients are of all races and age, the disease also affects all socioeconomic groups. CFS onset occurs frequently between 30 and 50 years of age, although it may occur at almost any age. It was estimated that in US, $0.42 \%$ of the adult population suffer from CFS, with a $70 \%$ of females. Higher and lower incidence approximations could be found in literature in many countries outside the US. Even if the prevalence of CFS in children and adolescents is vague, it seems to be lower than in adults, with comparable numbers of cases among both girls and boys. The CFS diagnosis is based on the patient-reported symptoms, as described in many case definitions, because no validated diagnostic test is available yet. The 2003 Canadian Clinical Case definition [6], proposed for clinical practice, better targets the main symptoms of CFS. Whereas the considerable attention media has put on CFS, the vast majority of patients are not been diagnosed. SPECT, PET and MRI brain imaging studies have found abnormalities in both white and gray matter. Many complications, independent from any other psychological disorder present, have been confirmed with cognitive tests. One study using electroencephalography data that differentiates CFS patients from patients with depression and from healthy controls, described a "signature".

Neuroendocrine studies have identified some abnormalities, in fact, the hypothalamic endocrine releasing hormone axes are often the opposite of what is found in major depression. Other studied described abnormal spinal fluid concentrations of lactic acid (and, hence, $\mathrm{pH}$ ) and unique spinal fluid proteins patterns. Last but not least, many studies in patients with CFS have found anomalies of the autonomic nervous system. Several patients reported a sudden begin of the disease, with infectious-like symptoms. There is good evidence that this disease can begin after several different viral and bacterial infections. Certainly, it seems questionable that one single infectious agent could be the cause of many CFS cases. Some evidence was found that, in patients with, several viruses causing latent, life-long infection could be reawakened or reactivated, although there is no certainty whether this is the cause or the effect of CFS. There are also evidences of chronic T cell activation and a recent study on the chimeric monoclonal antibody rituximab have provided indirect evidence for chronic B cell activation, as well. Many important progresses have been made to understand the underlying biology of CFS, but, so far, no accurate diagnostic test, or proven treatments, are available.

Ozone therapeutic capacities, such as its strong capacity to control the oxidative stress when administered in specific therapeutic doses, have grown much attention in the last few decades. A plethora of scientific proofs demonstrated that the most important molecular mechanisms behind the beneficial effect of ozone therapy are the activation of hypoxia inducible factor-1a (HIF-1a), nuclear factor of activated T-cells (NFAT), nuclear factorerythroid 2-related factor 2-antioxidant response element (Nrf2ARE), and activated protein-1 (AP-1) pathways. These mechanisms lead to the up- regulation of the endogenous antioxidant systems, to the activation of immune functions and to the control of inflammatory processes, which is important for correlating oxidative stress in chronic fatigue syndrome [12-22].

\section{Materials, Methods and Results}

At the Tirelli Medical Clinic, Pordenone, Italy, from February 2016 to December 2018, according to the SIOOT (Scientific Society of Oxygen Ozone Therapy) protocols, we have treated 100 patients with auto hemo-transfusion (GAE). The patients have been treated two times a week for one month and then, twice a month as maintenance therapy. The $80 \%$ of patients were females and $20 \%$ were males. Their ranged from 13 years to 60 years of age and the time from CFS diagnosis varied from 1 to 15 years. The level of fatigue was evaluated with the Fatigue Severity Scale which is used to estimate the severity of the symptom with a score ranging from 1 to 7 . Among the 100 patients with CFS treated, 70 patients (70\%) developed a significant improvement in symptomatology $(>50 \%$ improvement in symptoms). No side effects to ozone therapy have been reported. The study has been performed in compliance with the ethical values laid down by the Declaration of Helsinki, and informed consent documentation has been reviewed and agreed by the Independent Ethics Committee at the Tirelli Medical Clinic. The Chi-square test was used to calculate the differences according to age, gender, and adverse events, Univariate analyses have been performed to match the study arms; the unadjusted logic regression method was employed to assess crude odds ratios and 95\% confident intervals. Logistic progression models adjusted for major confounders like age and gender have been used to calculate adjusted odds ratios and $95 \%$ confident ratios. $\mathrm{P}<0.05$ has been considered statistically significant.

\section{Discussion}

Standardized medical treatments such as glucocorticoids, antidepressants, immunotherapy or metabolic drugs, are usually not beneficial in patients with CFS. We noted the positive clinical results obtained with ozone during the last decades of clinical experimentation in many diseases, mainly the consistent improvements in fatigue and wellbeing, that justified the use of ozonate autohemotherapy in patients with CFS. It is noteworthy that the efficacy of ozone therapy is due to its capacity of simultaneously activate many metabolic pathways that have gone astray [23-25]. In this study, seventy percent response rate obtained in our 100 patients demonstrates that ozone therapy could be a successful therapy in CFS. In conclusion, at our knowledge this is the largest study of patients with CFS treated with ozone therapy. Oxygen 
ozone therapy is an effective therapy in the treatment of CFS, as integrative/complementary medicine [26].

\section{References}

1. Arpino C, Carrieri MP, Valesini G, Pizzigallo E, Rovere P, et al. (1999) Idiopathic chronic fatigue and chronic fatigue syndrome: a comparison of two case-definitions. AnnIst Super Sanita 35: 435-441.

2. Bansal AS, Bradley AS, Bishop KN, Kiani-Alikhan S, Ford B (2011) Chronic fatigue syndrome, the immune system and viral infection. Brain Behav Immun 26: 24-31.

3. Barker E, Fujimura SF, Fadem MB, Landay AL, Levy JA (1994) Immunologic abnormalities associated with chronic fatigue syndrome. Clin Infect Dis 18 (suppl): S316-341.

4. Broderick G, Fuite J, Kreitz A, Vernon SD, Klimas N, et al. (2010) A formal analysis of cytokine networks in chronic fatigue syndromes. Brain Behav Immun 24: 1209-1217.

5. Caligiuri M, Murray C, Buchwald D, Levine H, Cheney P, et al. (1997) Phenotypic and functional deficiency of natural killer cells in patients with chronic fatigue syndrome. J Immunol 139: 3306-3313.

6. (2003) Canadian Expert Consensus Panel Clinical Case Definition for ME/CFS. J Chronic Fatigue Syndr 11: 7-116.

7. Cannon JG, Angel JB, Abad LW, Vannier E, Mileno MD, et al. (1997) Interleukin-1beta, interleukin-1 receptor antagonist, and soluble interleukin-1 receptor type II secretion in chronic fatigue syndrome. J Clin Immunol 17: 253-261.

8. Carlo-Stella N, Badulli C, De Silvestri A, Bazzichi L, Martinetti M, et al. (2006) A first study of cytokine genomic polymorphisms in CFS positive association of TNF-857 and IFN 8874 rare alleles. Clin Exp Rheumathol 24: $179-182$.

9. Carruther BM, van de Sande MI, De Meirleir KL, Klimas NG, Broderick G, et al. (2011) Myalgic encephalomyelitis International Consensus Criteria. J Intern Med 270: 327-338.

10. Conti F, Priori R, De Petrillo G, Rusconi AC, Arpino C, et al. (1994) Prevalence of chronic fatigue syndrome in Italian patients with persistent fatigue. Ann Ital Med Int 9: 219-222.

11. Fletcher MA, Zeng XR, Barnes Z, Levis S, Klimas NG (2009) Plasma cytokine in women with chronic fatigue syndrome. J Transl Med 7: 96.

12. Fukuda K, Straus S.E, Hickie I, Sharpe MC, Dobbins JG, et al. (1994) The chronic fatigue syndrome: a comprehensive approach to its definition and study. International Chronic Fatigue Syndrome Study Group. Ann Intern Med 15: 953-959.

ISSN: 2574-1241

DOI: 10.26717/BJSTR.2019.21.003602

Umberto Tirelli. Biomed J Sci \& Tech Res

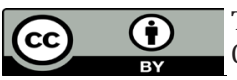

This work is licensed under Creative

Commons Attribution 4.0 License

Submission Link: https://biomedres.us/submit-manuscript.php
13. Konstantinov K, von Mikecz A, Buchwald D, Jones J, Gerace L, et al. (1996) Autoantibodies to nuclear envelope antigens in chronic fatigue syndrome. J Clin Invest 98: 1888-1896.

14. Kroenke K, Wood DR, Mangelsdorff AD, Meier NJ, Powell JB (1988) Chronic fatigue in primary care Prevalence patient characteristics and outcome. JAMA 206: 929-934.

15. Kruesi MJP, Dale J, Straus SE (1989) Psychiatric diagnoses in patients who have chronic fatigue syndrome. J Clin Psychiatry 50: 53-56.

16. Landay AL, Jessop C, Lennette ET, Levy JA (1991) Chronic fatigue syndrome: clinical condition associated with immune activation. Lancet 338: 707-712.

17. Moss RB, Mercandetti A, Vojdani A (1999) TNF-alpha and chronic fatigue syndrome. J Clin Immunol pp. 314-316.

18. Natelson BH, Haghighi MH (2002). Evidence for the presence of immune dysfunction in chronic fatigue syndrome. Clin Diagn Lab Immunol 9: 747-752.

19. Nishikai M (2007) Antinuclear antibodies in patients with chronic fatigue syndrome. Nippon Rinsho 265: 1067-1070.

20. Tirelli U, Chierichetti F, Tavio M, Simonelli C, Bianchin G (1998) Brain positron emission tomography (PET) in chronic fatigue syndrome: preliminary data. Am J Med 105: 54S-58S.

21. Tirelli U, Lleshi A, Berretta M, Spina M, Talamini R (2013) Treatment of 741 Italian patients with chronic fatigue syndrome. Eur Rev Med Pharmacol Sci 17:2847-2852.

22. Tirelli U, Marotta G, Improta S, Pinto A (1994) Immunological abnormalities in patients with chronic fatigue syndrome. Scand J Immunol 40: 601-608.

23. Tirelli U, Pinto A, Marotta G, Crovato M, Quaia M, et al. (2003) Clinical and Immunologic Study of 205 patients with chronic fatigue syndrome: A case series from Italy. Arch Intern Med 153: 116-117.

24. Tirelli U, Cirrito C, Pavanello M, Del Pup L, Lleshi A, et.al (2018) Oxygenozone therapy as support and palliative therapy in 50 cancer patients with fatigue - A short report. Eur Rev Med Pharmacol Sci 22(22): 80308033.

25. Tirelli U, Cirrito C, Pavanello M, Piasentin C, Lleshi A, et al. (2019) Ozone therapy in 65 patients with fibromyalgia: an effective therapy. Eur Rev Med Pharmacol Sci 23(4): 1786-1788.

26. Berretta M, Della Pepa C, Tralongo P, Fulvi A, Martellotta F, et al. (2017) Use of Complementary and Alternative Medicine (CAM) in cancer patients: An Italian multicenter survey. Oncotarget; 8(15): 2440124414.

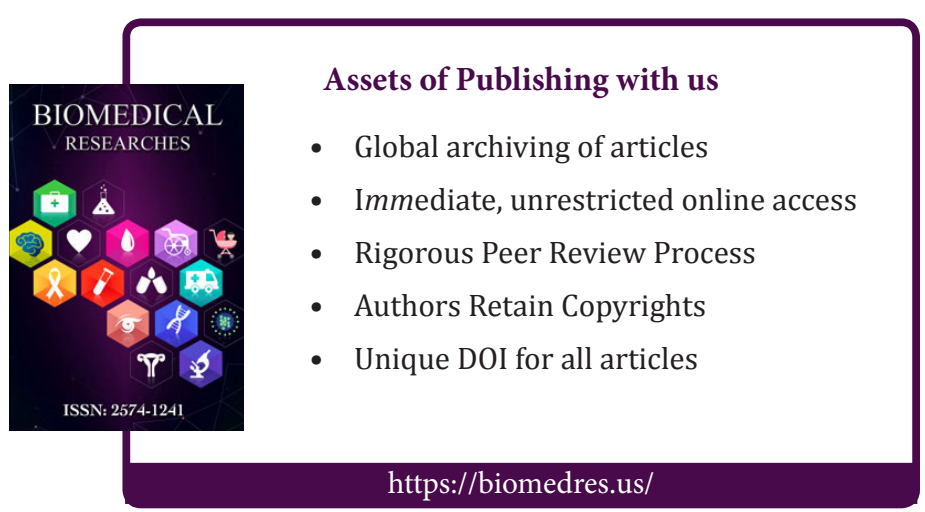

